\title{
Brain Heterotopia in Pharyngeal Region. A Morphological and Immunohistochemical Study
}

\author{
Anna Maria Buccoliero', Adele Caldarella', Bruno Noccioli², \\ Patrizio Fiorini ${ }^{3}$, Antonio Taddei ${ }^{4}$, Gian Luigi Taddei ${ }^{1}$ \\ 'Dipartimento di Patologia Umana e Oncologia, Università degli Studi di Firenze, Firenze, \\ ${ }^{2}$ U.O. Chirurgia Pediatrica II and ${ }^{3}$ U.O. Neonatologia e Patologia Neonatale, \\ Azienda Ospedaliera Anna Meyer, Firenze \\ ${ }^{4}$ Dipartimento di Area Critica Medico-Chirurgica Sezione Chirurgia Generale e D.C., \\ Università degli Studi di Firenze, Italy
}

\section{Summary}

Pharyngeal brain heterotopia is a congenital and generally biologically benign lesion. In contrast to brain heterotopia in the nose, the most common site of this lesion, brain heterotopia in the pharynx is very rare. Pharyngeal heterotopic tissue can be composed of various components, i.e., astrocytes, neurons, ependyma or choroid plexus, oligodendrocytes, retina, and, occasionally, neoplastic nodules. In contrast, nasal lesions are often only composed of astrocytes. We report a case of brain heterotopia in the pharyngeal region, diagnosed in a newborn female infant, causing serious respiratory distress. The infant underwent surgical excision of the lesion, and after 1 year of follow-up, she is recurrencefree. The mass, about $3 \mathrm{~cm}$ in diameter and showing no connection with encephalic structures, was characterized by numerous papillary structures and areas containing stellate-like or spindle cells focally forming nodules. Moreover, there was inflammatory infiltration, whereas mitoses, hemorrhages, and necroses were absent. Immunohistochemistry revealed a choroid plexus nature of the papillary formations (S-100, cytokeratins, transthyretin and vimentin-positive) and the presence of glial and neuronal cells in the remaining areas (glial fibrillary acidic protein, neuron-specific enolase, neurofilaments, synaptophysin, and S-100 positive). This case report confirms that the presence of choroid plexus is not uncommon and that pharyngeal brain heterotopia is usually benign.

Key words: Brain Heterotopia - Pharynx - Nasal glioma - Respiratory distress - Immunohistochemistry

\begin{abstract}
Abbreviations: $\mathrm{CK}=$ Cytokeratin, $\mathrm{GFAP}=$ Glial fibrillary acidic protein, NSE = Neuron-specific enolase, VIM = Vimentin, $\mathrm{SY}=$ Synaptophysin, $\mathrm{NF}=$ Neurofilament, $\mathrm{PBS}=$ Phosphate-buffered saline solution, $\mathrm{HE}=$ Hematoxylin-eosin
\end{abstract}

\section{Introduction}

Lesions composed of brain tissue occurring in the head and neck region, i.e., soft palate, pharynx, paranasal sinus, and nasal district have already been reported [17]. Most of these lesions, the so-called nasal gliomas, are found in or about the nose [16]. Nasal glioma has been estimated to occur in one in 20,000 to 40,000 live births [15]. In contrast, Bossen and Hudson [2], and Uemura et al. [27] reported on 18 and 17 cases of heterotopic brain tissue in the pharynx and the soft palate, respectively. In addition, four new cases have recently been described [20].

Heterotopic brain tissue is frequently diagnosed in either nasal or non-nasal location in newborn infants, whereas it is only rarely found in adults $[9,21]$.

Respiratory distress may be a characteristic symptom; nasal obstruction and epistaxis occur in intranasal lesions; cerebrospinal fluid rhinorrhea and meningitis

Address for correspondence: Gian Luigi Taddei, Dipartimento di Patologia Umana e Oncologia, Università degli Studi di Firenze, Viale G.B. Morgagni, 85, 50134 Firenze, Italy.

Tel.: +39+55-413756, Fax: +39+55-4379868.

E-mail: gl.taddei@unifi.it 
are occasionally observed in cases of intracranial extension. Furthermore, one can encounter obstruction of the lachrymal apparatus or visual impairment in subcutaneous external nasal location [8].

In general, biologically heterotopic brain tissue in the head and neck region is a benign lesion only occasionally recurring (4-10\% of the cases) [23] in cases of incomplete excision. Nevertheless, this lesion can lead to severe respiratory distress and death particularly in newborn infants $[3,6,25]$.

In contrast to the most common nasal gliomas, often exclusively composed of glial cells, heterotopic pharyngeal brain tissue can show ependyma, choroid plexus, and retinal or, rarely, neoplastic components [2].

We report an additional rare case of heterotopic pharyngeal-parapharyngeal brain tissue in a newborn infant.

\section{Clinical History}

A two-day-old female newborn infant was admitted to a pediatric hospital for severe respiratory distress. Pregnancy was uncomplicated. The child was delivered by cesarean section because of placental insufficiency. Before the symptoms appeared, the infant had been found to be healthy, weighing 3280 gr. with an Apgar score of 9 and 10 at the first and the fifth minute after birth, respectively. However, in the course of time, the infant began suffering from increasing respiratory distress necessitating tracheostomy. A physical examination re-
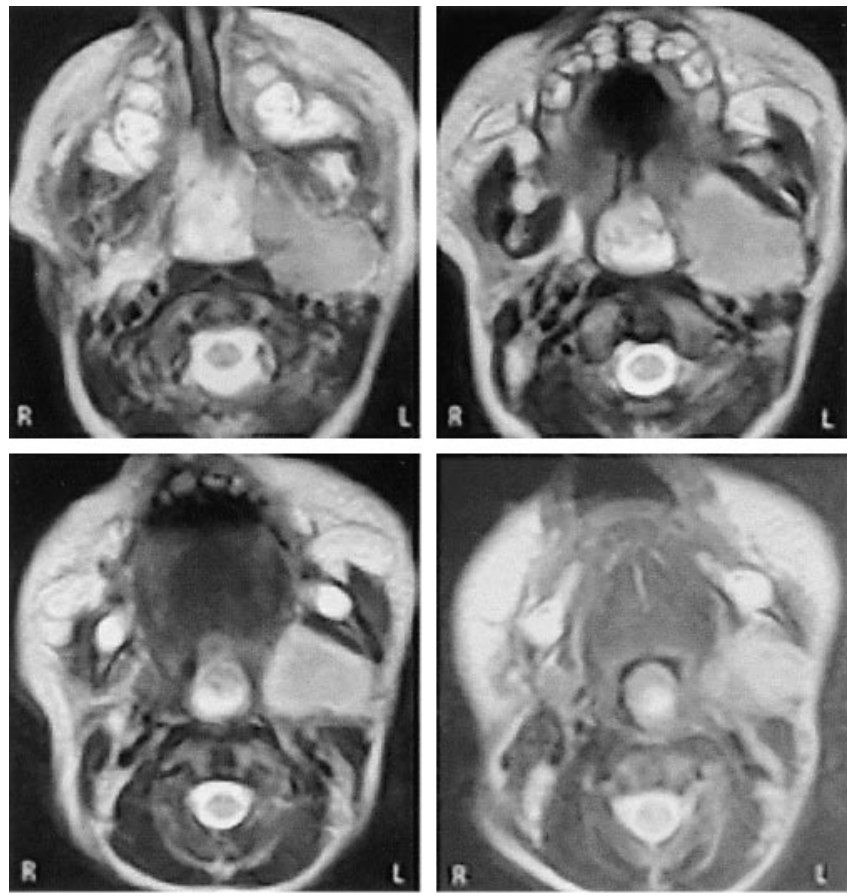

Fig. 1. Magnetic resonance scans of head-neck: a parenchymatous lesion of about $3 \mathrm{~cm}$ in diameter in left pharyngeal region. vealed a pearly gray round mass localized behind and above the uvula. The child underwent a radiography of the neck region revealing a left pharyngeal-parapharyngeal mass. Magnetic resonance imaging gave further evidence of the presence of a $3 \mathrm{~cm}$ lesion located between Rosenmuller's recess and the neurovascular bundle of the neck (Fig. 1). There was no connection between the lesion and cranial cavity. Tissue obtained from a biopsy was diagnosed as brain heterotopia. The mass was completely excised. No postoperative complications occurred, and after 1 year of follow-up, the child is alive and well with no signs of recurrence.

\section{Materials and Methods}

The specimen was fixed in $10 \%$ buffered neutral formalin, adequately sampled, and embedded in paraffin. Some sections were stained with hematoxylin-eosin (HE) for morphological evaluation, whereas further sections were mounted on electrostatic slides and used for immunohistochemical study. The primary antibodies used were as follows: monoclonal antibody against Ki-67 (Mib-1), cytokeratin (CK), glial fibrillary acidic protein (GFAP), neuron-specific enolase (NSE), vimentin (VIM), and synaptophysin (SY); multiclonal antibody against neurofilaments (NF); polyclonal antibody against transthyretin (TTR), and S-100 protein (for clone, dilutions, and sources of antibodies, Table 1). Sections designated for immunohistochemistry were air-dried overnight at $37{ }^{\circ} \mathrm{C}$, deparaffinized through xylene, and dehydrated through graded alcohol. Endogeneous peroxidase activity was blocked by immersing the specimens in a solution of $0.5 \% \mathrm{H}_{2} \mathrm{O}_{2}$. To recover antigenicity, slides incubated with TTR were treated with protease, whereas slides incubated with Mib-1, CK, GFAP, NSE, NF, SY and VIM antibodies were placed in a citrate buffer $(10 \mathrm{mM}, \mathrm{pH}$ 6.0 ), followed by microwave antigen enhancement ( $300 \mathrm{~W}$ for $40 \mathrm{~min}$ ). The sections were cooled down to room temperature, washed with phosphate-buffered saline solution (PBS, pH 7.4) and treated with normal horse serum (LAB VISION Corporation, Fremont, California) to reduce non-specific antibody binding. After extensive washing in PBS, the sections were incubated with biotinylated anti mouse IgG (LAB VISION) and then with streptavidin-biotin-peroxidase complex reagent (LAB VISION). After extensive washing with PBS, the slides were treated with 3,3'-diaminobenzidine-hydrogen peroxide (BioGenex, San Ramon, California) as a final indicator, and lightly counterstained with Mayer's hematoxylin. Negative control experiments were done by replacing the primary antibodies with non-immune mouse serum at an equivalent protein concentration.

\section{Results}

Light microscopy revealed various morphological features. Papillary structures sometimes inside cystic spaces and lined by cuboidal or cylindrical cells were identifiable (Fig. 2A). In addition, within thin fibro vascular stroma, we observed large areas characterized by 

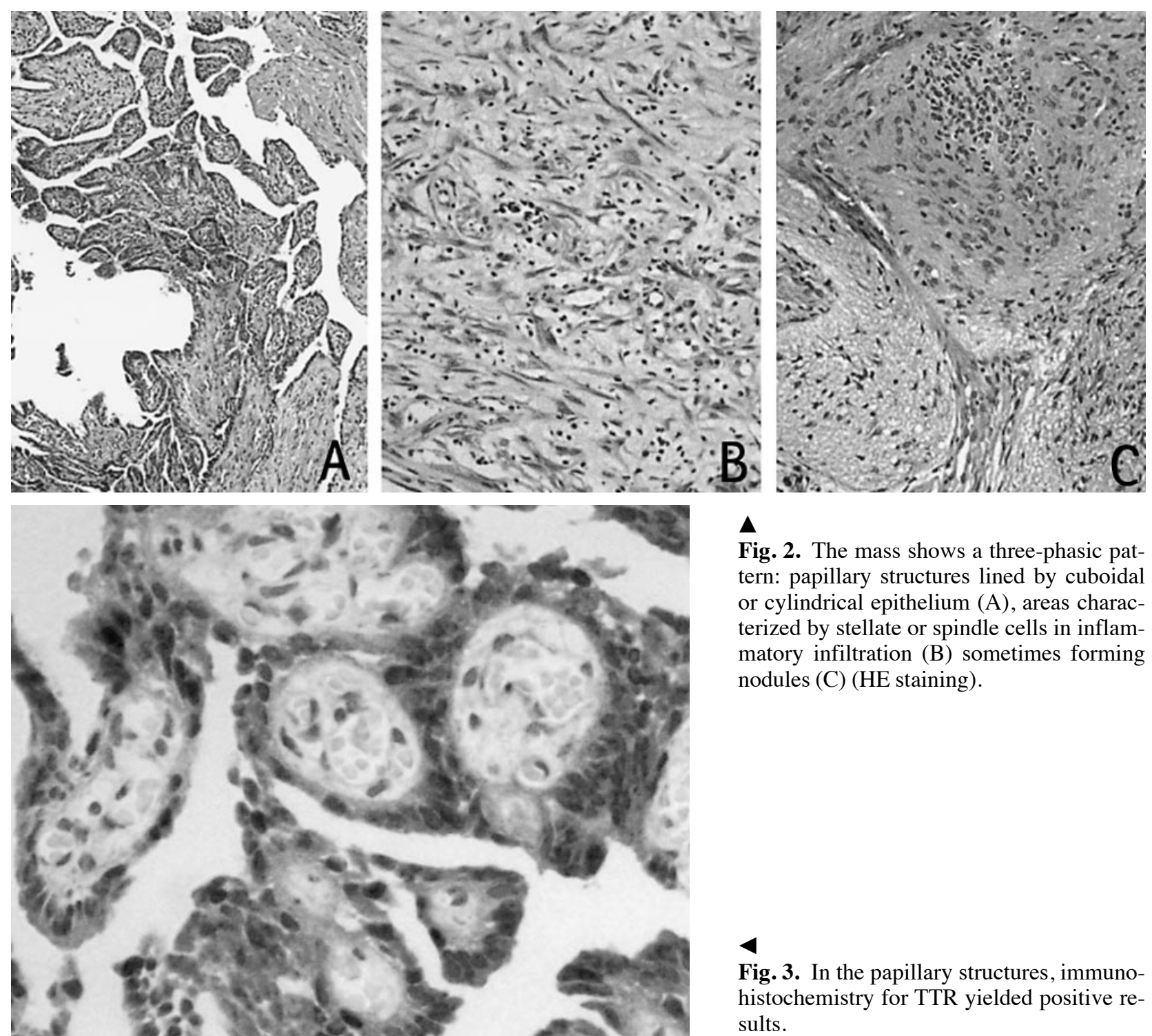

\section{$\Delta$}

Fig. 2. The mass shows a three-phasic pattern: papillary structures lined by cuboidal or cylindrical epithelium (A), areas characterized by stellate or spindle cells in inflammatory infiltration (B) sometimes forming nodules (C) (HE staining).

Fig. 3. In the papillary structures, immunohistochemistry for TTR yielded positive results.
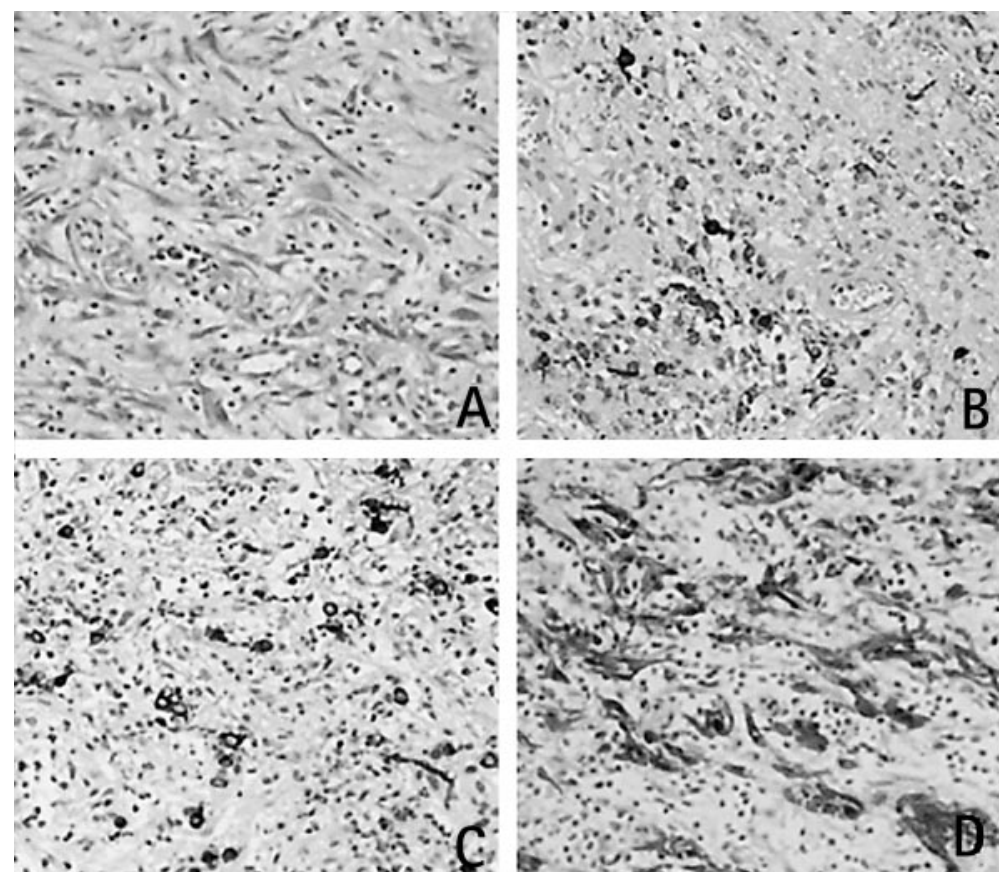

Fig. 4. In non-papillary areas, immunohistochemistry revealed both neurons and glia (A: HE; B: SY; C: NF; D: GFAP). 
$62 \cdot$ A. M. Buccoliero et al.

Table 1. Clone, dilution, and source of antibodies used and immunohistochemical results

\begin{tabular}{|c|c|c|c|c|c|}
\hline Antibody & Clone & Dilution & Source & $\begin{array}{l}\text { Papillary } \\
\text { areas }\end{array}$ & $\begin{array}{l}\text { Non papillary } \\
\text { areas }\end{array}$ \\
\hline Mib-1 & Mib-1 & $1: 80$ & $\begin{array}{l}\text { IMMUNOTECH } \\
\text { (Marseille, France) }\end{array}$ & - & - \\
\hline CK & AE1/AE3 & $1: 200$ & $\begin{array}{l}\text { BioGenex } \\
\text { (San Ramon, California) }\end{array}$ & + & - \\
\hline GFAP & ZCG29 & Prediluted & $\begin{array}{l}\text { Zymed Laboratories } \\
\text { (San Francisco, California) }\end{array}$ & - & + \\
\hline NSE & MIG-N3 & Prediluted & $\begin{array}{l}\text { BioGenex } \\
\text { (San Ramon, California) }\end{array}$ & - & + \\
\hline S-100 & - & $1: 2000$ & $\begin{array}{l}\text { Dako } \\
\text { (Glostrup, Denmark) }\end{array}$ & + & + \\
\hline VIM & V9 & $1: 2000$ & $\begin{array}{l}\text { BioGenex } \\
\text { (San Ramon, California) }\end{array}$ & + & + \\
\hline NF & DA2; FNP7; RMb020.11 & $1: 20$ & $\begin{array}{l}\text { Zymed Laboratories } \\
\text { (San Francisco, California) }\end{array}$ & - & + \\
\hline SY & Snp 88 & Prediluted & $\begin{array}{l}\text { BioGenex } \\
\text { (San Ramon, California) }\end{array}$ & - & + \\
\hline TTR & - & $1: 900$ & $\begin{array}{l}\text { Novocastra } \\
\text { (Newcastle, United Kingdom) }\end{array}$ & + & - \\
\hline
\end{tabular}

the presence of stellate-like cells or spindle cells (Fig. 2B); focally, they formed nodules of various size and were intersected by fibrous tissue septa (Fig. 2C). Diffuse inflammatory infiltration was visible, while there were no areas of necrosis, hemorrhage, mitotic figures, and atypical cells.

The results obtained by immunohistochemistry are summarized in Table 1 . In the papillary component, immunohistochemistry for CK, S-100, TTR (Fig. 3) and VIM yielded positive results, suggesting a choroid plexus nature. The remaining areas were positive for VIM, S-100, NSE, SY, NF and GFAP, disclosing both neurons and astrocytes (Fig. 4). The proliferation rate, evaluated by monoclonal antibody Mib-1, was low in the heterotopic cells.

\section{Discussion}

As early as 1900, Schmidt [24] hypothesized that nasal glioma originates from the herniation of neuroectodermal tissue. In the embryo, between the nasal and frontal bones, there exists a membrane, the so-called fonticulus naso-frontalis, which develops into foramen cecum. Dural and neuroectodermal tissues are present $[1,13]$ in the space delimited by fonticulus naso-frontalis and in the cartilaginous capsule of external nose during the first weeks of embryonal development. The closure of the craniofrontal sutures, before its complete intracranial retraction, would cut and sequestrate a mass of neuroectodermal tissue. The origin of brain heterotopia in pharyngeal and soft palate regions is less obvious than that of nasal glioma [2]. Nevertheless, similar to nasal glioma, many authors support the theory that defects in the developing skull cause an encephalocele-like condition [2]. This hypothesis, postulated to explain brain heterotopia in the lungs [12], is occasionally supported by the presence of bone defects $[2,19,28]$. The developmental abnormality and the biological benignity of these lesions are widely accepted. Consequently, the term "glioma", used in particular for nasal lesions, is questionable so that the term "cerebral heterotopia" has recently been proposed for this lesion [4]. Nevertheless, three previously published cases of non-nasal heterotopic brain tissue exhibited neoplastic areas $[2,11,16]$. Lee et al. reported a case of a melanotic neuroectodermal tumor appearing simultaneously with brain heterotopia in the oropharynx [16]; Gold et al. documented the presence of mixed oligo-astrocytoma in a palatal lesion associated with a cleft palate [11], and Bossen and Hudson reported an oligodendroglioma arising in heterotopic brain tissue in the soft palate and nasopharynx [2]. In addition, Chan and Lau reported a case of frontal lobe astrocytoma connected with an astrocytic lesion in the nasal cavity in a 34-year-old man [5]. However, Chan and Lau hypothesized that the nasal lesion derived from downward extension of the cerebral astrocytoma rather than from a neoplastic transformation of a nasal glial heterotopia with intracranial extension, or from a coexistence of two independent lesions. Thus, in brain heterotopia, neoplastic components are reported to occur exclusively in non-nasal location.

An additional difference between nasal and non-nasal location lies in the presence of various components in non- nasal location, whereas nasal lesions are exclusively composed of glial cells in general. In pharyngeal 
brain heterotopia, besides the constant presence of astrocytes, ependyma or choroid plexus, neurons, oligodendroglia, retina-like structures are detectable [2]. In contrast, in addition to astrocytes, cases with neuronal or leptomeningeal cells in nasal location have only rarely been reported [10, 18, 22].

In this case, choroid plexus is obvious and is documented immunohistochemically by TTR positivity. In the brain, TTR is uniquely synthesized by choroid plexus epithelium, representing its most typical and major biosynthetic product $[7,14,26]$.

Choroid plexus represents the most interesting feature of pharyngeal brain heterotopia. Bossen, reviewing the previously described cases, ascertained the presence of ependyma or choroid plexus in the pharyngeal and soft palate regions in 14 of 18 cases (78\%) [2], a finding supported by our case, indicating that their presence is not uncommon.

Identification of neuroglial tissue in the head and neck region allows for a variety of diagnostic possibilities: heterotopic tissue, encephalocele or teratoma [22]. A preoperative radiological study with a water soluble contrast agent, careful histopathological examinations of the entire specimen, and immunohistochemical evaluations are necessary to recognize the heterotopic nature of this rare and frequently benign lesion, sometimes presenting with severe symptoms.

\section{References}

1. Bianchi PM, De Vincentiis G, Andriani G, Masi R (1985) Mixed nasal glioma: clinico-statistical contribution. Acta Otorhinolaryngol Ital 5: 533-540

2. Bossen EH, Hudson WR (1987) Oligodendroglioma arising in heterotopic brain tissue of the soft palate and nasopharynx. Am J Surg Pathol 11: 571-574

3. Bratton AB, Robinson SHG (1946) Gliomata of the nose and oral cavity: a report of two cases. J Path Bact 58: 643-648

4. Burger PC, Scheithauer (1994) Tumors of the central nervous system. Atlas of tumor pathology, third series, fascicle 10, p 372-373. Armed Forces Institute of Pathology, Washington (AFIP)

5. Chan JKC, Lau W (1989) Nasal astrocytoma or nasal glial heterotopia? Arch Pathol Lab Med 113: 943-945

6. Cohen AH, Abt AB (1970) An unusual cause of neonatal respiratory obstruction: heterotopic pharyngeal brain tissue. J Pediatr 76: 119-122

7. Dickson PW, Aldred AR, Marley PD, Guo-Fen T, Howlett GJ, Schreiber G (1985) High prealbumin and transferrin levels in the choroid plexus of rat brain. Biochem Biophys Res Commun 127: 890-895

8. Dini M, Lo Russo G, Colafranceschi M (1998) So-called nasal glioma: case report with immunohistochemical study. Tumori 84: 398-402

9. Gallippi G, Raimondi E, Cannavo' C (1966) Rare case of astrocyte glioma of the nasal fossa. Folia Hered Pathol (Milano) 16: 27-34

10. Gambini C, Rongioletti F, Rebora A (2000) Proliferation of eccrine sweat ducts associated with heterotopic neural tissue (Nasal glioma). Am J Dermatopathol 22: 179-182
11. Gold AH, Sharer LR, Walden RH (1980) Central nervous system heterotopia in association with cleft palate. Plast Reconstr Surg 66: 434-441

12. Gonzalez-Crussi F, Boggs JD, Raffensperger JG (1980) Brain heterotopia in the lungs. A rare cause of respiratory distress in the newborn. Am J Clin Pathol 73: 281-285

13. Gundwald L (1910) Beiträge zur Kenntnis kongenitaler Geschwülste und Missbildungen an Ohr und Nase. Zt F Ohremhik 60: 210

14. Herbert J, Wilcox JN, Pham KC, Fremeau RT, Zeviani M, Dwork A, Soprano DR, Makover A, Goodman DS, Zimmerman EA, Roberts JL, Schon EA (1986) Transthyretin: A choroid plexus-specific transport protein in human brain. The 1986 S. Weir Mitchell Award. Neurology 36: 900-911

15. Hughes GB, Sharpino G, Hunt W, Tucker HM (1980) Management of the congenital midline nasal mass: a review. Head Neck Surg 2: 222-233

16. Lee SC, Henry MM, Gonzalez-Crussi F (1976) Simultaneous occurrence of melanotic neuroectodermal tumor and brain heterotopia in the oropharynx. Cancer 38: 249-253

17. Mills SE, Gaffey MJ, Frierson HF (1997) Tumors of the upper aerodigestive tract and ear. Atlas of tumor pathology, third series, fascicle 26, p 119-122. Armed Forces Institute of Pathology, Washington

18. Mirra SS, Pearl GS, Hoffman JC, Campbell WG (1981) Nasal "glioma" with prominent neuronal component. Arch Pathol Lab Med 105: 540-541

19. Moritz JD, Emons D, Wiestler OD, Solymosi L, Kowalewski S, Reiser M (1995) Extracerebral intracranial hamartoma with extension into parapharyngeal space. Am J Neuroradiol 16: 1279-1281

20. Behar MF, Muller S, Gerber ME, Todd W (2001) Heterotopic neuroglial tissue causing airway obstruction in the newborn. Arch Otolaryngol Head Neck Surg 127: 997-1002

21. Pasquini E, Farneti G, Giausa G, Biavati M (1998) A rare case of nasal glioma in adult age. Otolaryngol Head Neck Surg 118: 905-906

22. Patterson K, Kapur S, Chandra RS (1986) "Nasal gliomas" and related brain heterotopias: a pathologist's perspective. Pediatr Pathol 5: 353-362

23. Puppala B, Mangurte HH, McFadden J, Lygizos N, Taxy J, Pellettiere E (1990) Nasal glioma presenting as neonatal respiratory distress. Definition of the tumor by MRI. Clin Pediat 29: 49-52

24. Schmidt MB (1900) Ueber seltene Spaltbildungen im Bereiche des mittleren Stirnfortsatzes. Arch Path Anat Phys Klin Med 162: 340-370

25. Sinn DP, Wesseberg FA, Coln DA, Weinberg AE, Sklar RH (1981) Neonatal asphyxia secondary to Robin complex and neuroglia heterotopia of nasopharynx. Oral Surg Oral Med Oral Pathol 52: 137-141

26. Soprano DR, Herbert J, Soprano KJ, Schon EA, Goodman DS (1985) Demonstration of transthyretin mRNA in the brain and other extrahepatic organs in the rat. J Biol Chem 200: 11793-11798

27. Uemura T, Yoshikawa A, Onizuka T, Hayashi T (1999) Heterotopic nasopharyngeal brain tissue associated with cleft palate. Cleft Palate Craniofac J 36: 248-251

28. Wakai S, Nakamura K, Arai T, Nagai M (1983) Extracerebral neural tissue mass in middle cranial fossa extending into the oropharynx in a neonate. J Neurosurg 59: 692-696

Received: September 11, 2001

Accepted in revised version: November 12, 2001 